\title{
O CONFLITO COLOMBIANO NO SÉCULO XX: A PERSPECTIVA DAS LUTAS POR TERRAS E TERRITÓRIOS COMO DIREITO À TERRA E PAZ
}

\author{
Luís Felipe Perdigão de Castro ${ }^{1}$ \\ Miquelly Barbosa da Silva ${ }^{2}$
}

\section{RESUMO:}

$\mathrm{O}$ presente artigo reflete sobre o conflito colombiano no século $\mathrm{XX}$, em especial a dinâmica da legislação rural dentro dos processos de concentração e exclusão no campo. Parte-se, inicialmente, de um breve panorama histórico para, na sequência, debater as significações das lutas por terras e territórios, como busca por direitos e identidades sociais. O pano de fundo é a luta por terra como elemento transversal das violências contra comunidades camponesas, indígenas e afro-colombianas. O objetivo geral é, através de pesquisa bibliográfica e interpretação sociológica do direito, discutir as contradições e rupturas que permeiam as disputas e legislações agrárias da Colômbia.

Palavras-chave: Colômbia; terras e territórios; legislação agrária; identidades sociais.

\section{THE COLOMBIAN CONFLICT IN THE 20TH CENTURY: THE PERSPECTIVE OF THE STRUGGLES FOR LAND AND TERRITORIES AS A RIGHT TO LAND AND PEACE}

\begin{abstract}
:
This article reflects on the Colombian conflict in the 20th century, especially the dynamics of agrarian legislation within the processes of concentration and exclusion in the countryside. It begins with a brief historical overview and then discusses the meanings of struggles for land and territories, as a search for rights and social identities. The background is the struggle for land as a cross-cutting element of violence against peasant, indigenous and Afro-Colombian communities. The general objective is, through a bibliographical research and the sociological interpretation of the law, to discuss the contradictions and ruptures that permeate the agrarian disputes of Colombia.
\end{abstract}

Keywords: Colombia; lands and territories; agrarian law; social identities

\section{INTRODUÇÃO}

\footnotetext{
${ }^{1}$ Doutorando em Ciências Sociais, pela Universidade de Brasília (DELA/UnB). Mestre em Agronegócios (UnB), e graduado em Direito (UFOP). Integra os grupos de pesquisa: Estudos Comparados de Sociologia Econômica; BICAS; LEIJUS e, ainda, o Grupo de Estudos Comparados México, Caribe, América Central e Brasil (MeCACB), todos vinculados à Universidade de Brasília (UnB). Coordena o grupo Terras e Territórios na América Latina: interfaces conceituais entre Direito e Ciências Sociais (Unidesc). Professor de graduação e pós-graduação da Faciplac e Unidesc.

${ }^{2}$ Mestranda em Ciência Política (Unieuro). Integra o Grupo de Estudos Comparados México, Caribe, América Central e Brasil (MeCACB), vinculado ao Departamento de Estudos Latino-Americanos (ELA) da Universidade de Brasília (UnB). Desenvolve atividades junto à equipe do periódico Abya-yala: Revista sobre Acesso à Justiça e Direitos nas Américas, no âmbito das atividades do Laboratório de Estudos Interdisciplinares sobre acesso à Justiça e direitos nas Américas - LEIJUS. Professora de graduação, no curso de Direito do Unidesc.
} 
O panorama histórico da Colômbia, no presente trabalho, enfatiza os processos sociopolíticos e agrários mais recentes, compreendidos a partir do século XX. Nesse período, a Colômbia é um caso emblemático de polarização política e transformação dos espaços de poder, através da estreita relação entre as lutas sociais por terra, direito e paz. Em comparação a outras nações latino-americanas, a Colômbia se destaca como "un país con (gran) estabilidad institucional, un número insignificante de golpes de estado, la mayor cantidad de mandatarios elegidos por voto popular, con un congreso que muy pocas veces ha cerrado sus puertas, con una prensa libre". Não obstante toda a estabilidade institucional, o país apresenta nas últimas décadas "uno de los más altos índices de violencia en el mundo (URIBE, 2001, p. 26; GÓMEZ, 2005, p. 01).

Embora a violência e a privação a direitos possuam raízes antigas e remontem ao passado colonial, nas últimas sete décadas as disputas assumiram feições peculiares, dentro de um intenso conflito armado interno (CAI) ${ }^{3}$ que matou cerca de 220 mil pessoas, entre 1958 e 2012 (SUAREZ et al, 2014, pp. 31 e 33). São conflitos que "não tem um início claro, e suas raízes podem identificar-se com contendas antigas, do século XIX e das primeiras décadas do século XX” (GRISALES, 2013, p. 127). Apesar dos fatores multidirecionais, no centro da violência está a disputa por terras e territórios. Esse cenário sofreu uma série de agravamentos no século XXI, marcado pela "redistribución inconclusa, con las luchas campesinas del siglo XX, y el reconocimiento inacabado, con las luchas sociales de fin del siglo XX y principios del XXI" (HOFFMANN, 2016, p. 18).

$\mathrm{O}$ presente artigo reflete sobre o conflito colombiano no século $\mathrm{XX}$, em especial a dinâmica da legislação rural dentro dos processos de concentração e exclusão no campo. Parte-se, inicialmente, de um breve panorama histórico dos embates e legislações agrárias (tópico I) para, na sequência, debater as significações das lutas por terras e territórios, como busca por direitos e manifestação de identidades sociais (tópico II). O pano de fundo é a luta por terra como elemento transversal do repertório de violências contra comunidades camponesas, povos indígenas e afro-colombianos.

\footnotetext{
${ }^{3} \mathrm{O}$ termo CAI (conflito armado interno) denomina uma situação que não é, propriamente, uma guerra civil, não é também uma série de ações terroristas, nem se limita a um aumento abrupto de atos de violência isolados. O CAI reúne três características básicas: a) partes operam com estatutos jurídicos desiguais; b) as ações dos grupos armados respondem a um comando, que pode ser ou não similar a organização militar-hierárquica; c) há um propósito político ou ideológico definido que se relaciona com o controle de territórios (ONU, 2013, p. 41).
} 
O objetivo geral é, através de uma pesquisa bibliográfica e pela interpretação sociológica do direito, discutir as contradições e rupturas que permeiam as disputas agrárias e as legislações da Colômbia. $\mathrm{O}$ artigo não pretende fechar questão sobre um problema de pesquisa, nem apresenta conclusões definitivas. Trata-se de um estudo preliminar, ligado ao projeto de tese do autor, desenvolvido no Grupo de Estudos Comparados México, Caribe, América Central e Brasil - MeCACB/CNPq, orientado pela Profa. Rebecca Lemos Igreja, em sede do Departamento de Estudos LatinoAmericanos (ELA/ICS/UnB), da Universidade de Brasília.

\section{PANORAMA HISTÓRICO: O CONFLITO COLOMBIANO NO SÉCULO XX}

O território colombiano possui uma superfície de $1.141 .748 \mathrm{~km}^{2}$, localizado a noroeste da América do Sul e com acesso a diversas regiões hidrográficas (Oceano Pacífico e Atlântico, Mar do Caribe, bem como bacias dos rios Amazonas e Orinoco). Juridicamente, está em vigor a Constituição Nacional de 1991, que instituiu uma república presidencialista e unitária, organizada sob 32 departamentos, o distrito da capital (Bogotá), 1.121 municípios e os territórios indígenas. Em 2010, a população era de 45.508.205 habitantes, dos quais 49,4\% eram homens e 50,6\% mulheres. Bogotá é a cidade mais povoada (7.363.782 habitantes) e concentra, junto com as cidades de Medellín, Cali, Barranquilla e Cartagena, 40,6\% da população nacional (DANE, 2010, 2011a, 2011b). Esse rico espaço geográfico está inserido em uma dinâmica sociopolítica complexa. O acesso à terra ocorre em meio a valores culturais e simbólicos das categorias sociais, enfatizando significações distintas para o termo "terra" e "território":

Se diferencia del territorio, concebido como un espacio apropiado por un sujeto colectivo, negociado, moldeado por generaciones y habitado por grupos sociales (aliados o en disputa), pero también por mitos, relatos y antepasados. Si "la tierra" es un recurso medible, "el territorio" implica sujeto y subjetividades. No se define solamente por rasgos objetivables sino también por prácticas de uso, percepción y representación, es decir, por juegos de territorialidades que mantienen los actores con sus espacios (Di Meo 2011; Raffestin 1986). Sujetos y subjetivación. No existe territorio sin sujeto social que lo conozca y lo identifique. La noción de subjetivación define el proceso de construcción de este sujeto territorial, en el sentido de un sujeto de derechos, pero también de la historia de su propia historia. (HOFFMANN, 2016, 19). O grifo é nosso. 
Temas e agendas do meio rural permeiam a origem e o desenvolvimento dos embates colombianos no século $\mathrm{XX}^{4}$. Contudo, a consolidação das disputas não é recente e nos remete às antigas relações coloniais ${ }^{5}$, quando a América Latina entrou na Modernidade ${ }^{6}$ como a "outra face": dominada, explorada e encoberta (DUSSEL, 2005, p. 28). Dessa forma, a matriz colonial de poder sobre as terras denota que embora o colonialismo tenha praticamente chegado ao fim, é a colonialidade que marca as relações de poder contemporâneas (BALLESTRIN, 2013).

Assim, as velhas e novas formas de opressão herdadas historicamente do colonialismo desaguam no início do século $\mathrm{XX}$, com extensos latifúndios e plantações de café em Sumapaz, Quindío, Huila, no norte do Valle e de Sinú, além de grande produção comercial de bananas da "United Fruit Company" e de borracha na região amazônica (LEGRAND, 1988; MELO 2015). Por outro lado, os movimentos campesinos e a aproximação das demandas dos povos indígenas e afro-colombianos fizeram com que o problema agrário tomasse "la escena política" e "por primera vez como un problema nacional”, na medida em que se constituía obstáculo à industrialização e ampliação do mercado interno colombiano (MACHADO, 2009, p. $165)$.

Nesse período, os projetos de colonização se acentuaram, seguindo a ideia de que a solução passava pelo fortalecimento de uma classe média rural no campo (MACHADO, 2009, p. 184; LEGRAND, 1988, p. 05) ${ }^{7}$. A Lei no 200 de 1936, promulgada no governo de Alfonso López Pumarejo (1934-1938 e 1942-1945), considerada a primeira lei de reforma agrária do século XX, “marcó un cambio notorio en el tratamiento del problema agrario y renovó la legislación agraria que venía

\footnotetext{
${ }^{4} \mathrm{~A}$ disputa se desenvolveu principalmente no meio rural colombiano, nas vilas, aldeias e pequenas cidades, relativamente distantes e apartadas dos grandes centros urbanos e do poder. Portanto, é "uma guerra que muchos colombianos y colombianas no ven, no sienten, uma guerra que no los amenaza", de tal forma que aqueles que vivem longe do meio rural "ignoran que, por ejemplo, un acuerdo que pacte un cesse al fuego representa para esos campesinos y campesinas la diferencia entre quedarse o huir, entre vivir o morir" (SÁNCHEZ et al, 2014, p. 22).

${ }^{5}$ Mignolo (2010, p.12) sugere que a matriz colonial do poder "é uma estrutura complexa de niveis entrelaçados". A colonialidade se reproduz em uma tripla dimensão: a do poder, do saber e do ser. E mais do que isso: a colonialidade é o lado obscuro e necessário da modernidade; e a sua parte indissociavelmente constitutiva (Mignolo, 2003, p. 30).

6 A modernidade consiste no processo histórico no qual a Europa inicia o caminho para as hegemonias. Posteriormente, protagonizada pelos Estados Unidos, após a II Guerra Mundial (DUSSEL, 2010).

${ }^{7}$ Camponeses, indígenas e afrocolombinos foram empurrados para projetos agrários nas regiões de fronteira e em áreas públicas. Em 1924, uma nova instituição creditícia foi criada - o "Banco Agrícola Hipotecario" - para financiar a aquisição de terras e fomentar cooperativas agrícolas (Lei $\mathrm{n}^{\circ}$ 68). Pouco tempo depois, em 1926, houve o reconhecimento da função social da propriedade da terra (Lei $\left.\mathrm{n}^{\circ} 74\right)$, que autorizava o Estado a expropriar glebas e implementar procedimentos redistributivos. Após uma década, em 1936, o governo promulgou a lei de reforma agrária, tentando responder aos anseios de uma distribuição social que fosse além do mero parcelamento de áreas (Lei $\mathrm{n}^{\circ} 200$ ).
} 
construyéndose desde la colonia" (MACHADO, 2009, p. 136). Contudo, não foram impulsionadas mudanças no sistema de propriedade da terra, servindo a Lei $\mathrm{n}^{\mathbf{0}} 200$ e seus regulamentos à conformação de uma classe assalariada no campo (constituída por arrendatários e aparceros, a quem os latifundiários compravam as benfeitorias ou, simplesmente, faziam uso de vias jurídicas para tomá-las) (MELO, 2015, p. 02).

As lutas agrárias foram acumulando importantes debates e avanços, com apoio de grupos de esquerda como a "Unión Nacional Izquierdista Revolucionaria” (UNIR), o "Partido Comunista de Colombia" (PCC) e o "Partido Agrario Nacional" (PAN). A essa época, os trabalhadores sindicalizados nos anos 1920 e 1930 tornaram visíveis a exploração e precarização das condições de vida dos peões, camponeses e arrendatários, abrindo uma fase de mobilização frente aos conflitos rurais (MACHADO, 2009, p. 174). No bojo desse processo, as décadas de 1940 e 1950 representam um momento político especialmente delicado, agravando-se quando os partidos políticos radicalizaram suas disputas. Os problemas rurais foram acirrados e desencadeou-se uma onda de violência sem precedentes.

As guerrilhas colombianas têm parte de suas raízes na guerra civil que dilacerou o país no final dos anos 1940, provocada por um choque entre o partido conservador e o partido liberal, culminando com "La Violencia"8. Mais especificamente à dinâmica de terras e territórios, é importante destacar que as ondas de violência, entre 1951 e 1964, levaram mais de dois milhões de pessoas a migrarem em massa para as cidades, alterando a dinâmica da produção agrícola e gerando processos diferenciados de luta pela terra (MEERTENS, 2000). Considerando um período anterior, partindo de 1946, a maior parte dessa violência - implementada pelo Estado e pelas elites - se dirigiu contra pessoas e organizações rurais, como a Confederação Camponesa e Indígena. Foram assassinados entre 200 a 300 mil camponeses, sendo 2 milhões deslocados e expulsos de suas terras. Nos territórios invadidos foram impostas políticas do setor patronal, baseadas em cultivos comerciais de grande escala, como a cana-de-

\footnotetext{
${ }^{8} \mathrm{O}$ episódio que deflagrou a guerra civil foi o assassinato, em 09 de abril de 1948, de Jorge Eliécer Gaitán ${ }^{8}$. Na campanha presidencial, esse candidato contava com o apoio de grande parte dos trabalhadores e sua morte causou a indignação de operários e camponeses. Diante da repercussão do assassinato e da mobilização das classes populares, grupos conservadores colombianos que ocupavam o poder central (com apoio dos Estados Unidos) aprofundaram a repressão entre 1948 e 1953. Iniciou-se uma revolta popular conhecida como "El bogotazo", que se desdobrou em uma onda de violência por dez anos (1948-1958), no período chamado "La Violencia". Alguns autores consideram o período ainda maior, compreendido entre 1946 a 1966 (MEERTENS, 2000; CEARÁ, 2009; LEONGÓMEZ, 2006, p. 64, BECERRA, 2013, p. 165).
} 
açúcar e o algodão (BEDOYA, 2000; MONDRAGON, 2004; BECERRA, 2013; HOFFMANN, 2016).

Esse cenário - ínsito aos efeitos de "La Violência" - agravou-se com a vitória e posse do candidato conservador, Laureano Gómez (em 1950). Seu partido propôs, em 1953, uma nova Constituição inspirada no governo espanhol de Francisco Franco. Contudo, as alas moderadas de liberais e conservadores se opuseram a esse projeto e uma junta militar derrubou o governo. Com a instauração da Ditadura Militar, o General Rojas Pinilla assumiu o poder em 1953 e empreendeu esforços para desarticular as guerrilhas dos Llanos, usando armas, decretos e anistia. Contudo, as tratativas fracassaram e deram lugar a conexões políticas entre partidos e associações de grandes proprietários de terras. Houve, assim, o histórico acordo entre liberais e conservadores, dando origem à "Frente Nacional", que governou por décadas (1958-1974) alternando mandatos por partido.

A partir dos anos 1960 passam a coexistir grupos armados nominados de "Guerrilhas", caso das "Fuerzas Armadas Revolucionarias de Colombia" (FARC) e o "Ejército de Liberación Nacional" (ELN). Existiram também o "Ejército Popular de Liberación" (EPL) e o "Movimiento 19 de Abril" (M-19), desmobilizados no período de 1989 a 1990. Além desses, o "Partido Revolucionario de los Trabajadores" (PRT) e o “Movimiento Indígena Quintín Lame” (Quintín Lame), ativos nos anos 1980, foram gradativamente interrompidos a partir de 1991.

De outro lado, consolidaram-se grupos armados paraestatais, reconhecidos como "Paramilitares". É importante diferenciá-los, levando em conta que "la violencia contra la integridad física es el rasgo distintivo de la violencia paramilitar, mientras que la violencia contra la libertad y los bienes define la violencia guerrillera”. Em outras palavras, os paramilitares adotaram estratégias mais baseadas em homicídios, enquanto os guerrilheiros instrumentalizaram sequestros e destruições de patrimônio físico (SÁNCHEZ et al, 2014, p. 35). Estes, por sua vez, foram organizados com o aval do Exército Nacional Colombiano e se firmaram como principal defesa do empresariado agrícola, pecuarista, agroindustrial e de narcotraficantes (ARSON, 2004). Possuem bases regionais mais diversas, descentralizadas e autônomas que as guerrilhas, salvo um breve momento dos anos 1990, em que formaram uma federação paramilitar denominada "Autodefensas Unidas de Colombia" (AUC) (AMNISTÍA INTERNACIONAL, 2012). 
Além das guerrilhas e dos grupos paramilitares, outro agente importante no conflito é a "Fuerza Pública", composta por "Fuerzas Militares" (Exército, Marinha e Aeronáutica) e a "Policía Nacional". "La Fuerza Pública se centró en las detenciones arbitrarias, las torturas, los asesinatos selectivos y las desapariciones forzadas, así como en los daños colaterales" (SÁNCHEZ et al, 2014, p. 35).

No tocante às disputas por terras e territórios, a desmobilização de organizações paramilitares tem intensificado os deslocamentos forçados e a perda de áreas por camponeses, indígenas, afrodescendentes e outras comunidades. Em muitos casos, há uma clara relação entre a "actividad paramilitar y la apropiación constante de tierras" (AMNISTÍA INTERNACIONAL, 2012, p. 05).

Nos anos 1990, a questão agrária colombiana se orientou no contexto neoliberal (MACHADO, 1998, p. 21) e os anseios de modernização do campo levaram à "ley agraria de 1994" (REYES, 2015, p. 50). Além disso, o discurso e as medidas de combate ao tráfico de drogas ocuparam a agenda nacional. Os Estados Unidos da América (EUA), com base na diplomacia retaliativa e na mobilização militar, apoiaram diversas iniciativas, em especial, o Plano Colômbia ${ }^{9}$, durante o governo de Andrés Pastrana (1998-2002).

Os EUA destinaram ao referido plano, somente no ano 2000, cerca US\$ 1,5 bilhões, levando a Colômbia a tornar-se, entre 1999 e 2001, o terceiro maior receptor de assistência militar norte-americana, em termos globais. A estratégia de combate aos grupos armados, continuou com os governos norte-americanos seguintes, dando impulso, em 2002, às iniciativas do presidente Álvaro Uribe Vélez (2002-2010), favorável a soluções armadas. Uribe foi mais além e criou o Plano Patriota, uma ofensiva militar contra as FARC no sul da Colômbia, com assistência técnica e militar dos EUA (DIAZ-RIVILLAS, 2002, p. 175). Tanto o Plano Colômbia, como o Patriota, intensificaram a militarização e polarização da Colômbia ante seus vizinhos latinoamericanos. Contudo, não impediram o aumento da violência ${ }^{10}$ contra a população

\footnotetext{
${ }^{9}$ O Plano Colômbia foi um acordo bilateral assinado em 1999 com os Estados Unidos, durante os governos de Andrés Pastrana Arango e Bill Clinton e ratificado nos governos de Álvaro Uribe Vélez e Juan Manuel Santos. Estruturou-se a partir de cinco pontos estratégicos: promover negociações de paz com os grupos guerrilheiros, desenvolver a economia colombiana, realizar desenvolvimento social e democrático, lutar contra o "narcotráfico", reformar o sistema judicial e proteger os direitos humanos. Desse conjunto, os recursos para forças armadas somaram $67 \%$ dos investimentos. "La ayuda para los temas de derechos humanos incluía 15 millones de dólares que representaban un $1,46 \%$ y finalmente se designó sólo 1 millón de dólares para apoyar el proceso de paz. Esta suma representaba 0,09\% del total. " (DÍAZ, 2002; GRISALES, 2013, p. 128).

${ }^{10} \mathrm{O}$ aparato militar patrocinado através do Plano Colômbia facilitou a implementação de mega-projetos hidroelétricos, petrolíferos e de mineração, patrocinados pelo Banco Mundial e por empresas multinacionais. Além
} 
camponesa e povos indígenas (CARAVALLO E MENDONÇA, 2002). Além do combate ao narcotráfico, a dinâmica de terras e territórios na década de 1990 foi marcada pela Lei $\mathrm{n}^{\circ} 160$ de 1994. As políticas baseadas nessa lei foram apoiadas pelo Banco Mundial e, linhas gerais, não otimizaram significativamente a democratização de acesso à terra.

Entre 1996 y 2002, en la que el conflicto armado alcanzó su nivel más crítico como consecuencia del fortalecimiento militar de las guerrillas, la expansión nacional de los grupos paramilitares, la crisis del Estado, la crisis económica, la reconfiguración del narcotráfico y su reacomodamiento dentro de las coordenadas del conflicto armado. Esta tendencia fue sucedida por una etapa decreciente que va desde el año 2003 hasta hoy, y ha estado marcada por la recuperación de la iniciativa militar del Estado, el repliegue de la guerrilla y la desmovilización parcial de los grupos paramilitares (SÁNCHEZ et al, 2014, p. 33).

Partindo desses elementos, a trajetória anterior do conflito pode ser didaticamente organizada em quatro períodos: a) de 1958 a 1982, quando houve a transição da violência bipartidarista à violência generalizada; b) o período de 1982 a 1996, sob o contexto da guerra fria e consolidação do narcotráfico como tema da agenda nacional e global. Ocorreu a projeção política e expansão das guerrilhas, ao tempo em que surgiram os primeiros grupos paramilitares. As políticas públicas e estruturas do Estado entraram em colapso e um novo pacto constitucional foi promulgado (Constituição de 1991), entre processos de paz e reformas parciais; c) o período de 1996 a 2005 foi uma fase de agravamento dos conflitos armados. O Estado recompôs parte de suas forças e o combate ao narcotráfico se confundiu com as estratégias de combate ao conflito como um todo e, ainda, d) de 2005 a 2012 predominou a ofensiva militar do Estado, “debilitando pero no doblegando la guerrilla" (SÁNCHEZ, 2014, p. 111; GMH, 2009a; 2009b; 2012a; 2012b).

Em 2002, o governo de Juan Manuel Santos (2010-2014 e 2014-atual) iniciou os diálogos de paz com as Farc, em Havana, Cuba (GRISALES, 2013). Após quatro anos de negociações, Juan Manuel Santos e as Farc assinaram um acordo de paz, em 26 de setembro de 2016. Em 02/10/2016, os colombianos foram às urnas ${ }^{11}$ decidir se

disso, mais de um milhão de hectares da floresta colombiana foram contaminados por agentes químicos, sob o pretexto de combater o cultivo de coca. O desastre ecológico é conhecido como "Tormenta Verde" (CARAVALLO E MENDONÇA, 2002).

${ }^{11}$ O plebiscito foi aprovado pela Suprema Corte colombiana, em julho de 2016, mas os magistrados deixaram claro que a aprovação do acordo dependeria apenas da sanção presidencial (PALOMINO, 2016; SALEK, 2016). 
aprovavam o acordo de paz. Por uma diferença de 54 mil votos, o "não" se impôs ao "sim" (50,2\% a 49,8\%) e a proposta foi rejeitada" (PALOMINO, 2016; SALEK, 2016).

\section{LUTAS POR TERRA, DIREITOS E IDENTIDADES SOCIOCULTURAIS}

A descrição do conflito como "uma guerra civil de 50 anos" é uma visão reducionista da história colombiana. A questão diz respeito a um conflito armado interno, cuja origem e desenvolvimento remontam a mais de cem anos, envolvendo atores sociais diversos, massacres estatais e espoliação de terras. Nesse contexto, se inserem categorias sociais (camponeses, indígenas e comunidades afro-colombianas e outras) com dinâmicas peculiares, pois:

Así como la introducción de los sujetos de derecho "afrodescendientes" causó muchos debates en los años 19801990 en Colombia, y la de desplazados igualmente ocasionó discusiones al inicio del siglo XX (Osorio 2001), la construcción de un sujeto "campesino" distinto y equiparable a los indígenas y afrocolombianos suscita preguntas y dudas entre observadores, políticos y militantes. En efecto, los indígenas y afrodescendientes también son campesinos y sería arriesgado erigir fronteras entre estas categorías y propiciar así una etnización forzada de la sociedad, llevando a la par, eventualmente, problemas de fragmentación social y discriminación horizontal entre grupos étnicos y culturales. Sin embargo, al mismo tiempo, no se puede obviar el hecho de que los campesinos que no se reconocen como indígenas o afrodescendientes gozan de muy pocas herramientas políticas y jurídicas (...) (HOFFMANN, 2016, p. 19). O grifo é nosso.

Mesmo com as diferenças de tempo, espaço e categorias sociais, as relações agrárias na América Latina do século XX reproduzem a essência histórica de antigas práticas coloniais. As formas de dominação se reatualizam também através dos discursos de justificação e, assim, o aumento da produtividade, da eficiência e do aproveitamento racional das terras são argumentos que impulsionam/defendem a expropriação de áreas (CASTRO e IGREJA, 2017, p. 212), ao tempo em que "atualizam e contemporizam processos que supostamente teriam sido apagados, assimilados ou superados pela modernidade" (BALLESTRIN, 2013, p. 91). A exploração e a opressão "do passado" são reatualizadas sem o colonialismo, por dinâmicas de poder que reafirmam a concentração de terras, capital e informação (BALLESTRIN, 2013; CASTRO, 2016, p. 88; CASTRO e IGREJA, 2017, p. 211). Na confluência de fatores 
históricos, a luta por terra é o elemento transversal do repertório de violências colombianas:

La apropiación, el uso y la tenencia de la tierra han sido motores del origen y la perduración del conflicto armado. [...]. Todos los informes ilustran la gradual convergência entre la guerra y el problema agrario (despojos violentos, concentración ociosa de la tierra, usos inadecuados, colonizaciones y titulaciones fallidas). Pero a los viejos problemas se suman otros nuevos, que muestran las dinámicas inauguradas por el narcotráfico, la explotación minera y energética, los modelos agroindustriales y las alianzas criminales entre paramilitares, políticos, servidores públicos, élites locales económicas y empresariales, y narcotraficantes. (SÁNCHEZ et al, 2014, p. 13). O grifo é nosso.

As elites agrárias vêm, desde séculos, se opondo ferrenhamente à democratização do acesso às glebas, especialmente contra as políticas de reforma agrária e às reintegrações/restituições às categorias sociais expulsas de suas áreas. Apesar dessas dificuldades, as comunidades engendram resistências fáticas $\mathrm{e}$ institucionais, pois a resistência "se constitui como elemento que aproxima os diferentes grupos tradicionais" (COSTA, 2016, p. 02). Tais formas de resistência decorrem do potencial transformador das comunidades rurais, mediante o exercício de sua “imaginação geográfica e política” (HOFFMANN, 2016, p. 19):

[...] no se trata solo de legitimar la voz de nuevos sujetos resistentes a la dominación, sean subalternos o poscoloniales, sino de reconocer la capacidad de los actores de pensarse a sí mismos por fuera de las normas impuestas por uno u otro tipo de actores hegemónicos. La imaginación política abre horizontes que no entran en categorías preestablecidas: "Necesitamos entonces desarrollar una nueva inteligencia. Esta no pasa ni por la glorificación de la diferencia y la alteridad, ni por alguna fascinación romántica por el pobre, el oprimido y el subalterno" (MBEMBÉ, 2003, 190). O grifo é nosso.

A busca por expressões concretas da imaginação geográfica e política das categorias sociais rurais gera pressões importantes sobre o sistema jurídico. Exemplo disso é a aliança negro-indígena, que permitiu a aprovação do artigo transitório no 55 à Constituição Colombiana de $1991^{12}$. O dispositivo permitiu a criação de uma comissão

\footnotetext{
${ }^{12}$ Essa Constituição notabilizou-se pelo fato de ter reconhecido, de uma forma praticamente inédita, a natureza pluriétnica e multicultural da Colômbia, dando um lugar específico tanto às comunidades indígenas, quanto às comunidades negras. Tal reconhecimento veio acompanhado ainda de uma nova política fundiária, que pode levar ao reconhecimento de quase um quarto do território nacional como "resguardo indigena" (cerca de 2\% da população colombiana), assim como institui uma nova figura de direito territorial, que beneficia as comunidades negras rurais (cerca de $10 \%$ a $12 \%$ da população) (ARRUTI, 2000, p. 95).
} 
para redigir o projeto sobre direitos territoriais de comunidades negras rurais da costa do Pacífico (ARRUTI, 2000, p. 96). Além de impactar o reconhecimento das terras, o artigo 55 foi regulamentado pela lei 70, de 1993, que definiu as "comunidades negras" como "o conjunto de famílias de ascendência afrocolombiana que possuem uma cultura própria, compartilham de uma história e têm suas próprias tradições e costumes dentro da tradição campo-povoado e conservam consciência de identidade que as distingue de outros grupos étnicos". Apoiando e regulamentando tais inovações legais, foram decretadas uma série de outras normas ${ }^{13} \mathrm{e}$ em todos esses dispositivos legais pressupôsse "a existência de formas coletivas de regulação do acesso à terra" (ARRUTI, 2000, p. 97). Por esse viés, as formas de agir e viver impactam a visão, o acesso e a regulação sobre a terra:

$\underline{\text { Los derechos territoriales no se limitan a los derechos de }}$ propiedad, aunque los incluyen. Se fundan en el reconocimiento por terceros (vecinos, administraciones, Gobiernos) del derecho a acceder y gozar de una porción del espacio, sea como propietario (con título de propiedad), poseedor (con derecho reconocido pero sin título), tenedor (arrendatario, mediero, etc.) u ocupante (sin derecho legal, principalmente sobre baldíos de la nación). Este criterio se combina con la dimensión individual o colectiva de la posesión o propiedad y el tipo de validación (figura legal) que le es asociada. En su conjunto, estos elementos caracterizan figuras territoriales, construidas a lo largo de la historia agraria del país y reveladoras de las relaciones de fuerza y la capacidad de negociación de los actores rurales (HOFFMANN, 2016, p. 23). O grifo é nosso.

Nesse sentido, a legitimidade do sujeito étnico na América Latina (indígena e rural, em sua maioria) vem se impondo também pela via de transformações constitucionais, legislativas, territoriais e políticas (DUARTE, 2015). As estratégias incluem as lutas por reconhecimento das concepções socioculturais das comunidades, através das legislações e políticas públicas, ao tempo em que se destacam as diferenças entre as noções de terra - como um meio e local de produção - e de território - como um lugar ou terra de identidade, de auto reconhecimento e/ou de ocupação histórica, em uma perspectiva integradora das relações econômicas e de poder, base de recursos naturais e de referências simbólico-culturais (HAESBAERT, 2012).

\footnotetext{
${ }^{13}$ Sobre o Direito de Propriedade Coletiva (decreto 1745), sobre a criação de instituto de pesquisas de etnoeducação (decreto 2249), sobre a representação de comunidades negras e indígenas no interior dos organismos governamentais de desenvolvimento (decreto 2314), assim como sobre a criação de um espaço de interlocução entre essas comunidades e o Estado, pensados enquanto "instancias territoriais e nacionais" (decreto 1371).
} 
Nessa linha, os arranjos territoriais retratam momentos particulares da história e das dinâmicas sociais. Enquanto regimes de acesso à terra, esses arranjos são expressões das identidades sociais no campo. Assim, na Colômbia, além dos direitos de propriedade e posse, surgiram "las dotaciones en propiedad privada, los resguardos coloniales y republicanos, los territorios colectivos de comunidades negras (Ley 70, de 1993), las zonas de reserva campesina (Ley 160, de 1994), las dotaciones de tierras a las víctimas de desplazamiento (Ley 1448, de 2011) (HOFFMANN, 2016, p. 26).

Otras figuras se refieren al derecho de acceder y usar porciones del espacio, por parte no de particulares sino de los gobiernos nacionales y locales. Son las áreas de parques naturales, reservas forestales, terrenos baldíos, reservas territoriales urbanas, patrimonio nacional, es decir, las zonas cuyo sujeto legítimo de derecho es el Estado. Constituyen espacios sustraídos al intercambio mercantil y pueden alimentar los programas de adjudicación (Banco de Tierras, Fondo Nacional Agrario). Pueden, en algún momento, entrar en competencia con otras territorialidades rurales, como es el caso frecuente de áreas protegidas con territorios colectivos y resguardos. Son también áreas que los Gobiernos pueden dar en concesiones petroleras o mineras, con las consiguientes restricciones a la adjudicación a campesinos (HOFFMANN, 2016, p. 26). O grifo é nosso.

Assim, nas últimas décadas, dentre diversas configurações territoriais reconhecidas pelo direito colombiano estão os territórios coletivos de comunidades negras (Lei $\mathrm{n}^{\mathbf{o}}$ 70, de 1993). Tais áreas decorreram não somente da vertente multiculturalista da Constituição Colombiana de 1991, mas, sobretudo, dos movimentos sociais do fim do século XX (em luta contra os "acaparamientos de tierras por la agroindústria transnacional"). Os membros dos territórios coletivos são representados por conselhos comunitários, que cuidam de assuntos locais, engendrando organizações com arquitetura própria e desprovidas de "prerrogativas de gobierno" (HOFFMANN, 2016, pp. 24 e 26). Outras importantes figuras territoriais traduzem a relação entre identidades sociais, formas de acesso/valoração da terra e as legislações. É o caso da Lei no 160 de 1994, que previu as Zonas de Reservas Campesinas (ZRC's), o Ordenamento Ambiental Territorial (OAT) e estruturas como as Unidades Ambientais Campesinas (UACA) e as Juntas de Ação Comunal (JAC).

As Zonas de Reservas Campesinas (ZRC's) remontam aos movimentos e organizações sociais das regiões de Guaviare, La Macarena e, mais genericamente, aos deslocamentos camponeses do fim do século XX (ORDÓÑEZ, 2012; RINCÓN, 2009). 
São um projeto de ancoramento produtivo e econômico do campesinato em zonas marginalizadas (HOFFMANN, 2016), que visam promover um acesso mais equitativo às glebas "para los campesinos, no con alcances estructurales como resulta indispensable, sino por lo menos, en el ámbito territorial" (MÉNDEZ, 2011) ${ }^{14}$. Enquanto instrumento de ordenamento territorial, são uma estratégia para a desconcentração de terras, proteção de recursos ambientais e apoio à produção camponesa. Seu caráter, porém, foi limitado pelo contexto da década de 1990, quando as legislações agrárias foram aplicadas com viés neoliberal (REYES, 2015).

Além da ZRC, o conceito de "Ordenamiento Ambiental Territorial” (OAT) se firmou como critério regulador do acesso às glebas, relacionando-se com a função social e ambiental da propriedade. $\mathrm{Na}$ visão das organizações campesinas, esse ordenamento deve se estruturar combinando elementos "fundamentales para que las áreas protegidas sean zonas de vida y para la paz". Tais elementos se fundam no reconhecimento dos camponeses como sujeitos de direitos, como sujeitos de conservação do meio ambiente e, por fim, pela concepção de reordenamento territorial ambiental para todo o país. Dentro dessa lógica, "la vereda"15 é uma espécie de unidade territorial, para se pensar o planejamento ambiental e territorial" (ANZORC, 2014 REYES, 2015, p. 08). No âmbito do ordenamento ambiental territorial estão as "Unidades Ambientales Campesinas" (UACA) ${ }^{16}$, consideradas espaços onde "lo ambiental es primordial en la tenencia de la tierra" (LONDOÑO BOTERO, 1997; ANZORC, 2014; REYES, 2015).

A proposta das "Unidades Ambientales Campesinas" - UACA (como unidades básicas de manejo ambiental) e das "Juntas de Acción Comunal" - JAC (como estruturas organizativas básicas de decisões internas e de relacionamento com o Estado) foram esforços para concepção do ordenamento ambiental e territorial com bases

\footnotetext{
${ }^{14}$ As Zonas de Reserva Campesina (ZRC) se enmarcan en esta ley dentro de los procesos de colonización donde el Instituto Colombiano de Reforma Agraria (INCORA) desarrollaba actividades sujetas: [...] a las disposiciones relacionadas con los recursos naturales renovables y del medio ambiente y tendrán, como propósitos fundamentales, la regulación, limitación y ordenamiento de la propiedad rural, eliminar su concentración y el acaparamiento de tierras baldías a través de la adquisición o implantación de mejoras, fomentar la pequeña propiedad campesina y prevenir [...] la descomposición de la economía campesina del colono y buscar su transformación en mediano empresario (Artículo 79, Capítulo XIII) (MINISTERIO DE AGRICULTURA Y DESARROLLO RURAL, 1994).

15 "Vereda", na Colômbia, é um tipo de bairro rural composto por arredores e vizinhanças, onde existem terras acessadas de diversas formas, em especial propriedades privadas e posses. "Cada vereda suele tener su propia escuela primaria y su expresión organizativa está institucionalizada en la Junta de Acción Comunal (JAC) " (REYES, 2015, p. 52).

${ }^{16} \mathrm{O}$ ordenamento ambiental e produtivo requer avançar na identificação das potencialidades produtivas e ecológicas dos territórios, "permitindin planejar que planeen dentro de ellos una zonificación ambiental que defina las zonas productivas de cada vereda" (LONDOÑO BOTERO, 1997; ANZORC, 2014; REYES, 2015).
} 
relacionais. Isso diz respeito a uma relação que parte de um manejo ambiental de área privada (UACA) conectado com o manejo sob instância decisória coletiva $\left(\mathrm{JAC}^{17}\right)$ :

Esta propuesta espacial-política (territorial) no prioriza la relación individuo-Estado, sino la relación individuocomunidad-Estado, buscando una relación comunal con el Estado, priorizando decisiones comunales sobre las del individuo y la propiedad privada. Por esta razón, estructuras organizativas como las JAC cobran particular importancia en la organización territorial. Con estos ejemplos vemos como el campesinado de las ZRC demanda reconocimiento territorial más allá de los derechos de propiedad- a través de su participación en proponer estrategias de ordenamiento territorial donde lo ambiental puede estar incluido en vez de aislado, como un aspecto diferencial de la construcción territorial (REYES, 2015, p. 53). O grifo é nosso.

Assim, a riqueza dos arranjos territoriais de comunidades campesinas, indígenas e negras na Colômbia traduzem a luta não apenas por terra, mas a busca por territórios como espaços de paz, participação e dignidade.

Em contraste a essas estratégias e conquistas, o Estado e as elites agrárias realizam, na prática, artimanhas jurídicas e métodos de violência física e psicológica contra camponeses, indígenas e afro-colombianos (SÁNCHEZ et al, 2014, p. 22; WALDMANN, 1999, p. 32; LAIR, 2003, p. 93). Essa dinâmica reflete repertórios de violência múltiplas, como assassinatos seletivos, massacres, mortes de civis em confrontos, atentados terroristas, ataques a populações e bens civis. Nesse rol, os assassinatos seletivos são o meio utilizado por grupos armados que mais provocou vítimas, chegando a 150 mil mortos, isto é, 9 em cada 10 homicídios oriundos do conflito (GMH, 2009a; 2009b; 2012a; 2012b; AMNISTÍA INTERNACIONAL, 2012). Outras modalidades de violência estão presentes, "el secuestro, la tortura, la desaparición forzada, el desplazamiento forzado, la violencia sexual, las minas antipersonal y el reclutamiento ilícito" (FAJARDO, 2002; SÁNCHEZ, 2014).

Para além - e de forma concatenada às violações físicas e psicológicas existem outras dimensões de violência, que atinem a identidades sociais e culturais. "Se trata, además, de una violencia fundada em una manera de concebir la tierra, de ver el mundo y de entender las relaciones entre seres humanos y naturaliza". Ou seja, ocorre um enfrentamento entre uma visão estritamente econômica da terra (como fonte de

\footnotetext{
17 JAC significa "Junta de Acción Comunal", estruturas organizativas nas zonas rurais colombianas "y no se consideran que sean parte del aparato estatal ni del padrinaje político" (LONDOÑO, 1997, p. 93).
} 
rentabilidade e meio de produção) e outra concepção da terra "como madre y sustento de la vida espiritual, física, social y cultural (SÁNCHEZ et al, 2014, p. 22).

Há, portanto, uma dimensão sociocultural para a terra, que amplia o significado da luta e do direito para as comunidades tradicionais (CASTRO, 2017, p. 10). As nuances culturais desses grupos "atrelam ao território o reforço da tradição. Daí porque, não raramente, a utilização da terra pelas coletividades tradicionais despreza o referencial da propriedade privada e se afasta de uma exploração ambientalmente degradante". Não se trata apenas de patrimônio ou fonte de renda, pois, "a terra é o lugar da cultura, seja na acepção agrícola do termo (cultivo), seja no sentido de celebração dos antepassados (culto)" (COSTA, 2016, p. 02). Por esse viés, a luta por terras sintetiza a busca por direitos, que vão desde um "lugar" para a "moradia, saúde e educação" até, e principalmente, o direito das comunidades viverem autonomamente nesses espaços, enquanto territórios de vida, dignidade e de reprodução sociocultural. (CASTRO, 2017, p. 02).

Embora a violência e a privação a direitos sobre a terra possuam raízes antigas e remontem ao passado colonial, o conflito armado interno (CAI) ocupa destaque trágico no século XX, matando cerca de 220 mil pessoas, entre 1958 e 2012 (PÉREZ et al, 2014, p. 03). Esses números equivalem "a la desaparición de la población de ciudades enteras como Popayán o Sincelejo". As vítimas não-letais também são numerosas e, somente em 2013, o Registro Único de Vítimas (RUV) reportou 25.007 desaparecidos, 1.754 vítimas de violência sexual, 6.421 menores recrutados por grupos armados e 4.744.046 pessoas deslocadas compulsoriamente (SÁNCHEZ et al, 2014, pp. 31 e 33$)$.

No tocante às terras e territórios, desde a abertura econômica dos anos 1990, registrou-se o desaparecimento de 700 mil hectares de cultivos tradicionais e o empobrecimento da produção de alimentos em áreas camponesas, indígenas e afrocolombianas. Paralelamente, houve a expansão de cultivos ligados a agrocombustíveis e a extração de recursos naturais na forma de "land grabs" (estrangeirização de terras). Nesse processo, $42 \%$ da população deslocada sofreu perdas efetivas de terras rurais, sendo $90 \%$ dos abandonos motivados por atos de violência (FAJARDO, 2002). O processo de despojo influiu significativamente no aumento da concentração de terra que, para o ano 2010, chegou a 0.94 no coeficiente Gini (IBAÑEZ, 2010). Caso emblemático são as vítimas do "desplazamiento forzado" (deslocamentos forçados, em 
tradução livre), cuja gravidade no direito internacional é de crime contra a humanidade ${ }^{18}$.

Como fenômeno massivo, sistemático e de longa duração, o "desplazamiento forzado" se relaciona com o controle de terras e territórios estratégicos, podendo chegar a cinco milhões o número de pessoas deslocadas, dos quais $70 \%$ são vítimas menores de idade. Os impactos diretos do deslocamento forçado de camponeses, indígenas e afrocolombianos são o desenraizamento, degradação da qualidade de vida, amontoamento, fome e enclausuramento nos lugares onde se estabelecem de forma precária. A vida nas cidades os confronta com muitas humilhações, exclusões, discriminações raciais, étnicas, de classe, etc. (FRAGA e GONZALEZ, 2015, p. 32).

Dessa forma, as lutas por terras e territórios engendradas por comunidades camponesas, indígenas e negras ocorrem sob permanente preconceito da sociedade 'não tradicional' e mesmo do Estado (COSTA, 2016; CASTRO, 2017). Portanto, são categorias sociais vítimas da exclusão e da concentração agrária. Ao mesmo tempo, são protagonistas de "imaginação geográfica e política" (HOFFMANN, 2016), capazes de gerar arranjos territoriais que ultrapassam as concepções rígidas de propriedade privada e posse. Assim, são povos que aglutinam atuação política e se inserem nas disputas por terra e cidadania (CASTRO, 2017, p. 08).

Por fim, a violência e o preconceito contra camponesas, indígenas e negros tentam legitimar a negação de direitos sobre as terras e difundir a falsa ideia de "que esses grupos não possuem sequer a capacidade de entender e absorver elementos de mudança social". Não por outra razão são associados “à ideia de atraso, de passado e, mesmo, de pobreza" (CASTRO, 2015, p. 92; 2017, p. 18). Diante desse vasto repertório de demandas, significações e violências, a história do conflito colombiano é, também, a história das lutas por terras e territórios como cenário de direitos em disputa e espaços de vida e paz.

\section{CONSIDERAÇÕES FINAIS}

As comunidades camponesas, indígenas e negras são protagonistas de históricas lutas sociais por terra, território e identidade social e, simultaneamente, vítimas do conflito e de sua invisibilização. A violência na perspectiva dessas

${ }^{18}$ A transferência forçada de uma população é tipificada na letra "d", item 1, art. $7^{\circ}$, Estatuto de Roma. 
comunidades as tornam não apenas as vítimas mais numerosas, mas as que se inserem mais profundamente nas lutas por terra e território, revelando uma disputa que se desenvolve principalmente no meio rural colombiano, nas vilas, aldeias e pequenas cidades. Portanto, o conflito armado traz a reboque uma série de demandas sociais e humanitárias de vítimas que reivindicam a restituição de terras, territórios e recursos do meio rural.

As lutas por terras e territórios, como centralidade do conflito, não podem ser compreendidas apenas pelo discurso de regulamentação/defesa de propriedades e posses ou de reparações econômicas. Nessa linha, os arranjos territoriais retratam momentos particulares da história e das dinâmicas sociais. Há, portanto, uma dimensão sociocultural para a terra, que amplia o significado da luta e do direito para as comunidades tradicionais (CASTRO, 2017, p. 10). Não se trata apenas de patrimônio ou fonte de renda, pois, a luta por terras sintetiza a busca por direitos, que vão desde um "lugar" para a "moradia, saúde e educação" até, e principalmente, o direito das comunidades viverem autonomamente nesses espaços, enquanto territórios de vida, dignidade e de reprodução sociocultural. (CASTRO, 2017, p. 02).

Assim, na Colômbia, além dos direitos de propriedade e posse, surgiram "las dotaciones en propiedad privada, los resguardos coloniales y republicanos, los territorios colectivos de comunidades negras (Lei 70, de 1993), las zonas de reserva campesina (Lei 160, de 1994), las dotaciones de tierras a las víctimas de desplazamiento (Lei 1448, de 2011) (HOFFMANN, 2016).

Por fim, questão agrário-territorial tem se agravado e tornado as perspectivas de paz ainda mais difíceis. Em 2016, os colombianos foram às urnas e, por uma diferença pequena, o acordo de paz com as Farc foi recusado. Cenários como esse, mostram que uma visão eminentemente jurídica ou militar do confronto produziu, ao longo de décadas, mais divisões que consensos. O que se perde é a paz, manifesta também na autonomia das comunidades em suas terras e territórios.

\section{REFERÊNCIAS}

AMNISTÍA INTERNACIONAL. Colombia: La ley de Víctimas y de Restitución de Tierras. Análisis de Amnistía Internacional. Amnesty International Publications. International Secretariat Peter Benenson House. Editorial Amnistía Internacional (EDAI). Valderribas. Madrid: Espanha. 21p. 2012. 
ANZORC. Asociación Nacional de Zonas de Reserva Campesina. Ordenamiento ambiental, derechos campesinos: Ruta para la construcción de paz. II Congreso colombiano de áreas protegidas. Áreas protegidas: Territorios para la vida y la paz. Bogotá, Colombia. Julio 16 de 2014.

ARSON, C. The peace process in Colombia with the Autodefensas Unidas de Colombia. Washington: Woodrow Wilson Center. Latin American Program. 2004.

ARRUTI, J.M.A. Direitos étnicos no Brasil e na Colômbia: notas comparativas sobre hibridização, segmentação e mobilização política de índios e negros. Horizontes Antropológicos. RS: Porto Alegre, v. 6, n. 14, p. 93-123, nov. 2000.

BALLESTRIN, L. América Latina e o giro decolonial. Decolonial turn and Latin America. Revista Brasileira de Ciência Política, Brasília, n. 11, p. 89-117, 2013.

BEDOYA, R.R. El desplazamiento forzado y la pacificacion del país. Enfoques y metodologías sobre el hábitat: memorias de una experiencia pedagógica. Ensayos Forum, $n^{\text {o }}$ 15, 13p. 2000.

BECERRA, A. J. El periodo de la violencia en Colombia y el uso de las imágenes del terror, 1948-1965. Antropología Experimental, n. 13, p.151-165, 2014.

CASTRO, E. G. Juventude Rural no Brasil: processos de exclusão e a construção de um ator político. Revista Latinoamericana de Ciencias Sociales, Niñez y Juventud, v. 7 , p. 179-208, 2009.

CASTRO, L. F. P. Agricultura familiar: perspectivas e desafios para o desenvolvimento. Revista Eletrônica Espaço Acadêmico (Online), v. 17, p. 142-154, 2017.

A luta pela terra como luta por direitos: desafios e perspectivas das comunidades tradicionais no campo brasileiro. Revista Brasileira de Sociologia do Direito, v. 4, p. 137-160, 2017.

. Os contratos de arrendamento rural no Brasil: origens históricas e marcos jurídicos. Revista Brasileira de História do Direito, v. 2, p. 136-156, 2016.

Acesso à Terra e Arrendamentos Rurais: Perspectiva Comparada entre Brasil e Colômbia. Revista de Direito Agrário e Agroambiental, v. 2, p. 222, 2016.

Acesso contratual à terra e arrendamentos rurais: uma compreensão à luz dos clássicos. Revista Percurso (Online), v. 8, p. 85-110, 2016.

Agricultura familiar na América Latina: a difusão do conceito e a construção de sujeitos políticos. Revista Brasileira de Sociologia do Direito, v. 3, p. 73-97, 2016. 
CASTRO, L. F. P.; IGREJA, R. F. A. M. L. Estrangeirização de Terras na Perspectiva das Formas de Colonialidade no Agro Latino-Americano. Revista de Estudos e Pesquisas sobre as Américas, v. 11, 2017. No prelo.

CAVallaro, J; MEndonÇA, M. Perigos do Plano Colômbia 2002. Disponível em: http://www.dhnet.org.br/direitos/militantes/cavallaro/planoscolombia.html Acesso em: 15. Março. 2016.

CEARÁ, D. B. FARC-EP: o mais longo processo de luta revolucionária da América Latina. História Social, n. 17, p. 203-224, segundo semestre, 2009.

CORTÉS, P.M. Ley de víctimas y restitución de tierras en Colombia en contexto. Berlín, Forschungs und Dokumentationszentrum Chile-Lateinamerika (FDCL). Transnational Institute (TNI). 35p. 2013.

COSTA, Y. Comunidades tradicionais: pelo direito de existir e de resistir. Jornal da Escola Superior da Defensoria Pública da União, nº 07, Ano 02, p. 01-12, 2016.

CONGRESO DE LA REPÚBLICA. Ley de justicia y paz, 975 de julio 25. Bogotá, Congreso de la República.2005

Ley de víctimas y restitución de tierras, 1448 de junio 10. Bogotá, Congreso de la República. 2011.

DANE. Departamento Administrativo Nacional de Estadística de Colômbia. Dimensión social-Población. 2011a. Disponível em: http://www.dane.gov. co. Acessado em 25 de março de 2017.

Departamento Administrativo Nacional de Estadística de Colômbia. La visibilización estadística de los grupos étnicos colombianos.2010. Disponível em: http://www.dane.gov.co. Acessado em 25 de março de 2017.

- Departamento Administrativo Nacional de Estadística de Colômbia.

Estimaciones de población 1985-2005 y proyecciones de población 2005-2020. 2011b. Disponível em: http://www.dane.gov.co. Acessado em 25 de março de 2017.

DIAZ-RIVILLAS, B. Política Exterior de los EEUU hacia Colombia: el paquete de ayuda de 1.300 millones de dolares de apoyo al Plan Colombia y la región andina. América Latina Hoy. Salamanca, v.31, p.145-186, 2002.

DUARTE, C. (Des)encuentros en lo público. Gobernabilidad y conflitos interétnicos en Colombia. Tese de dout. Departement d'Anthropologie, Université Paris, París.2015. 
DUSSEL, E. Europa, modernidad y eurocentrismo. Em Lander, Edgardo (coord.). La colonialidad del saber: eurocentrismo y ciencias sociales, perspectivas latinoamericanas. Buenos Aires: Clacso.2000.

FAJARDO, D. Tierra, poder político y reforma agraria y rural. Cuadernos Tierra y Justicia, No. 1. Bogotá. ILSA. 2002.

FRAGA, P.C.P; GONZALEZ, G.M. Conflito armado na Colômbia e suas consequências para crianças e jovens. Desidades, Rio de Janeiro , v. 8, p. 3039, set. 2015.

FRANCO, S.; SUAREZ, C.M.; NARANJO, C.B.; BÁEZ, L.C.; ROZO, P. Efeitos do conflito armado sobre a vida e a saúde na Colômbia. Ciência e saúde coletiva, Rio de Janeiro, v. 11, p. 1247-1258, Jan. 2006.

ONU. Oficina en Colômbia del Alto Comisionado de las Naciones Unidas para los Derechos Humanos. Compilación de jurisprudencia y doctrina nacional e internacional. Protocolo II. Volume III. Bogotá: Plaza y Janes Editores; 2003.

GALlEGO, C. M. FARC-EP. Notas para una historia política 1958-2006. Universidad Nacional de Colombia, Bogotá: Univerdad Nacional de Colombia, 2008.

GARCÍA, A. A dónde va Colombia?: de la república señorial a la crisis del capitalismo dependiente. Temis, 1981. Antonio. Sociología de la reforma agraria. Bogotá, Cruz del Sur. 238p. 1973.

GIL, G. Viajeros de ausencia: desplazamiento forzado y acción colectiva en Colombia. Tese de doutorado. Madrid, Universidad Complutense de Madrid. 2009.

HOFFMANN, O. Divergencias construidas, convergencias por construir. Identidad, territorio y gobierno en la ruralidad colombiana. Revista Colombiana de Antropología, Enero-Junio/2016, p.17-39, 2016.

IBAÑEZ, A.M. Intervención en el Simposio La cuestión de la Tierra en Colombia, octubre 6, Universidad Nacional de Colombia. 2010.

GÓMEZ, P.B. Dimensión simbólica del conflicto sociopolítico y cultural de jóvenes en seis contextos locales de Colombia. Revista da Associação Nacional dos Programas de Pós-Graduação em Comunicação. E-compós. Brasília, v.11, n.3, p. 1-30, 2008.

GRISALES, S.P. Colômbia: a memória em meio à guerra. Tempo Social, USP, v. 25, p. 62-78, 2013. 
GRUPO DE MEMORIA HISTÓRICA - GMH. Comisión Nacional de Reparación y Reconciliación. Memorias en tiempo de guerra: repertorio de iniciativas. Bogotá, Puntoaparte. 2009a.

El despojo de tierras y territorios. Aproximación conceptual. Bogotá: CNRR/IEPRI, 2009b.

Justicia y paz. Tierras y territorios en las versiones de los paramilitares. Bogotá: Taurus Semana, 2012a.

Nuestra vida ha sido nuestra lucha. Resistencia y memoria en el Cauca indígena. Bogotá: Taurus Semana, 2012b.

La Rochela. Memorias de un crimen contra la justicia. Bogotá: Taurus Semana, 2010a.

GUZMÁN CAMPOS, G.; FALS BORDA, O. La violencia en Colômbia. $2^{\text {a }}$ ed. Bogotá: Editorial Taurus. Tomo I. 2005.

HAESBAERT, R. O mito da desterritorialização: do fim dos territórios à multiterritorialidade. Rio de Janeiro: Bertrand Brasil. 2012.

HERNÁNDEZ, L.H. Dimensiones Históricas y Socio-económicas del Conflicto Armado en Colombia. En Diálogos de La Habana: Miradas Múltiples desde la Universidad. Pp. 17-58. Bogotá: Universidad Nacional de Colombia. 2013.

LEONGÓMEZ, E. P. Uma Democracia Sitiada. RJ: Biblioteca do Exército, 2007.

LONDOÑO BOTERO, R. Los sindicatos y las juntas de acción comunal en Colombia. América Latina Hoy. N.17, pp. 87-102. 1997.

MACHADO, A. Ensayos para la Historia de la Política de Tierras en Colombia. De la colonia a la creación del Frente Nacional. Bogotá: Editorial Gente Nueva, 2009.

La cuestión agraria en Colombia a fines del milenio. Bogotá: El Áncora Editores. 1998.

MBEMBÉ, A. Réponses Autour d'un livre: de la postcolonie. Essai sur l'imagination politique dans l'Afrique contemporaine, Paris, Karthala, 2000. Politique Africaine, 3 (91), p. 171-194, 2003.

MELO, V.M. Ordenamento Territorial Na Colômbia Como Proposta De Reforma Agrária. Anais do Seminário América Latina: Cultura, História e Política. Uberlândia: MG. 18 a 21 de maio de 2015 . 
MÉNDEZ, Y. A. Zonas de reserva campesina-ZRC, Un instrumento de la política de tierras en clave a la reforma agraria. Agencia Prensa Rural, v. 13, 2011.

MEERTENS, D. Ensayos sobre tierra, violencia y género. Hombres y mujeres en la historia rural de Colombia 1930-1990. 1ª Edición. Bogotá, Universidad Nacional de Colombia, Centro de Estudios Sociales, CES, 458 p. 2000.

MINISTERIO DE AGRICULTURA. Desarrollo Rural de Colômbia. Ley 160 de 1994. Bogotá: 1994.

ORDÓÑEZ, F.G. Zonas de reserva campesina. Elementos introductorios y de debate. Bogotá: Incoder-ILSA. Sinpeagricun. 2012.

PALOMINO, S. Os jovens gritam pela paz na Colômbia. El País, 29-09-2016.

Disponível em http://www.ihu.unisinos.br/560677-os-jovens-gritam-pela-paz-nacolombia. Acesso em 15.março.2017

PÉREZ, G.J; AGUILERA, M.; GALVIS, L.A; OTERO, A; SÁNCHEZ-JABBA, A;

REYES, M. R. Territorio y ambiente en las Zonas de Reserva Campesina de Colombia.

Eutopía - Revista de Desarrollo Económico Territorial, n. 8, p. 45/56, 2015.

RINCÓN, J.J. Diversos y comunes: elementos constitutivos del conflicto entre comunidades indígenas, campesinas y afrocolombianas en el departamento del Cauca. Análisis Político, n.65, p.53-93, 2009.

SALEK, S. 4 pontos para entender o que acontece na Colômbia após rejeição do acordo de paz. BBC Brasil. 03/10/2016. Disponível em: http://www.bbc.com/portuguese/internacional-37546993. Acesso em 15.março.2017.

SÁNCHEZ, G; SUAREZ, A; GONZÁLEZ, F; UPRIMNY, R; RIAÑO, P; LINARES, P; WILlS, M.E; COLORADO, J. A; BELlO, M.N. et al. ; Basta ya! Colombia: Memorias de guerra y dignidad. Informe General Grupo de Memoria Histórica. Imprensa Nacional, Bogotá, p. 1-432, 2014.

URIBE, M. Nación, ciudadano y soberano. Medellín: Corporación región, 2001. 